\title{
La jurisprudencia existente acerca de la indumentaria del trabajador y otros elementos que afectan a su aspecto e imagen externa durante el trabajo
}

\author{
Existing jurisprudence on clothing of the worker \\ and other elements that affect their appearance and external \\ image during work
}

\author{
Tomás Sala Franco* \\ Catedrático Emérito de Derecho del Trabajo y de la Seguridad Social \\ Universidad de Valencia. Estudio General
}

Recibido: $1 / 2 / 2021$

Aceptado: 8/2/2021

doi: https://doi.org/10.20318/labos.2021.6047

Resumen: $\quad \begin{aligned} & \text { Partiendo de la doctrina del "equilibrio de derechos" del Tribunal Constitucional } \\ & \text { sobre la solución de los conflictos de concurrencia entre derechos constitucio- } \\ & \text { nales, se analiza la jurisprudencia de los principales Tribunales acerca del con- } \\ & \text { flicto entre la libertad de empresa y el derecho a la propia imagen del trabajador } \\ & \text { en relación la indumentaria de éste en el trabajo. }\end{aligned}$
Palabras clave: Libertad de empresa. Derecho al honor, intimidad y propia imagen. Indumen-
taria del trabajador. Jurisprudencia.
Abstract: $\quad \begin{aligned} & \text { Starting from the doctrine of the "balance of rights" of the Constitutional Court } \\ & \text { on the solution of conflicts of concurrence between constitutional rights, the } \\ & \text { jurisprudence of the main Courts about the conflict between the freedom of } \\ & \text { company and the right to own image of the worker is analyzed in relation to his } \\ & \text { clothing at work. }\end{aligned}$
Feywords:
Freem of company. Right to honor, privacy and own image. Worker's clothing.
Jurisprudence.

1. La doctrina jurisprudencial del Tribunal Constitucional en materia de derechos fundamentales del trabajador: la "doctrina del equilibrio entre derechos constitucionales en conflicto". La celebración de un contrato de trabajo no supone la pérdida para el trabajador de los derechos fundamentales que la CE le reconoce como ciudadano (SS.TC 38/1981, de 23 de Noviembre y $88 / 1985$, de 19 de Julio). Por tanto, no bastará con la sola alegación del interés empresarial para restringir los derechos fundamentales del trabajador dada la posición prevalente que éstos tienen en nuestro ordenamiento (SS.TC 99/1994, de 11 de Abril y 6/1995, de 10 de Enero). 
Pero los derechos fundamentales del trabajador no son derechos absolutos sino que se encuentran sometidos a límites, debiendo ejercitarse respetando otros derechos igualmente protegidos por la CE, tales como el derecho de libertad de empresa del empresario, concretable en su poder de dirección y organización del trabajo. Así pues, la concurrencia de derechos constitucionales enfrentados obligará siempre a analizar las circunstancias concurrentes en cada caso para la solución del conflicto.

Para solucionar estos conflictos, la jurisprudencia del Tribunal Constitucional ha elaborado la denominada "doctrina del equilibrio de los derechos constitucionales", consistente básicamente en lo siguiente:

10) No hay duda, según ha manifestado en repetidas ocasiones el Tribunal Constitucional a partir de la STC 38/1991, de 23 de Noviembre, de que los derechos fundamentales poseen no solo una eficacia vertical frente al Estado sino también una eficacia horizontal entre los particulares y, singularmente, en las relaciones laborales entre empresarios y trabajadores, "dado que en un Estado Social de Derecho como el que consagra el Art. 1 de la CE no puede sostenerse que el titular de tales derechos no lo sea en la vida social" (STC 18/1984, de 7 de Febrero), señalando que "la celebración de un contrato de trabajo no implica la privación en modo alguno para una de las partes, el trabajador, de los derechos que la Constitución le reconoce como ciudadano". Lo que se ha justificado por cuanto las organizaciones empresariales no forman "mundos separados y estancos del resto de la sociedad ni la libertad de empresa que establece el Art. 38 CE legitima que quienes prestan servicios en aquéllas por cuenta y bajo la dependencia de sus titulares deban soportar despojos transitorios o limitaciones injustificadas de sus derechos fundamentales y libertades públicas, que tienen un valor central en el sistema juridico constitucional" (por todas, SS.TC 88/1985, de 19 de Julio; 106/1996, de 12 de Junio, 98/2000, de 10 de Abril, 80/2001, de 26 de Marzo; o 196/2004, de 15 de Noviembre).

$\left.2^{\circ}\right)$ Resulta igualmente claro para el Tribunal Constitucional que tales derechos fundamentales del trabajador no son derechos absolutos o ilimitados que deban imponerse sin más a los demás derechos concurrentes, sino que, al contrario, vienen limitados, no solo intrínsecamente por su propia naturaleza y características, sino también extrínsecamente, esto es, por la existencia de otros derechos constitucionalmente reconocidos (por todas, STC 11/1981, de 8 de Abril).

3o) Se hace preciso, pues, compaginar la existencia de derechos posiblemente contradictorios, problema que el Tribunal Constitucional soluciona a través de la «doctrina del equilibrio de los derechos constitucionales", no tanto en base a un principio de jerarquización entre los derechos constitucionales dando prioridad a los derechos fundamentales sobre los demás derechos reconocidos, sino en base a un principio de equilibrio y proporcionalidad entre todos ellos, exigiendo en todo caso el respeto del contenido esencial del derecho fundamental, esto es, de "aquella parte del derecho que es absolutamente necesaria para que los intereses jurídicamente protegidos que dan vida al derecho resulten real, concreta y efectivamente protegidos"(STC 11/1981, de 8 de Abril).

Así pues, las limitaciones de un derecho fundamental solo pueden tener lugar y estar justificadas si superan el "juicio de proporcionalidad", concretable en los tres juicios siguientes:

a) El "juicio de idoneidad" o de "adecuación de la medida", esto es, si tal limitación es susceptible de conseguir el objetivo propuesto con la misma. 
b) El "juicio de necesidad", esto es, si tal limitación es necesaria, en el sentido de la inexistencia de otra medida limitativa menos agresiva con el derecho fundamental en juego para conseguir el propósito con igual eficacia.

c) El "juicio de proporcionalidad en sentido estricto", esto es, si se derivan de la limitación más ventajas para el interés empresarial que perjuicios para los derechos del trabajador (por todas, SS.TC 99/1994, de 11 de abril; 6/1995, de 10 de Enero; 66/1995, de 8 de Mayo; 55/1996, de 28 de Marzo; 207/1996, de 16 de Diciembre; 204/1997, de 25 de Noviembre; 207/1996, de 27 de Diciembre; 37/1998, de 17 de Febrero; 98/2000, de 10 de Abril; o 186/2000, de 10 de Julio).

$\left.4^{\circ}\right)$ De esta manera, en aplicación del anterior esquema interpretativo del Tribunal Constitucional, los derechos fundamentales del trabajador recogidos en el Art. 18 de la CE limitarán los poderes empresariales de selección, de organización y de control de los trabajadores subordinados, que forman parte esencial del derecho de libertad de empresa reconocido en el Art. 38 de la CE y serán limitados a su vez por ellos.

Será con este bagaje instrumental con el que la jurisprudencia ordinaria debe igualmente abordar la solución de estos conflictos de derechos, a la vista de la pobreza o escasez de normas reguladoras (legales y aún convencionales) sobre el ejercicio de los derechos fundamentales del trabajador y el poder de dirección empresarial.

\section{Los derechos en juego en materia de indumentaria personal e imagen externa del trabajador} Cuando se enfrentan el interés del empresario en que sus trabajadores den una determinada "imagen de empresa" - referida no solamente a la vestimenta que deba usar en el trabajo (exigencia de un determinado uniforme de empresa, de faldas o de zapatos de tacón a las trabajadoras o de chaqueta y corbata a los trabajadores; prohibición de llevar pantalones vaqueros, zapatillas de deporte o determinados símbolos religiosos, políticos o filosóficos; prohibición o limitación en el uso de pendientes, "piercing" o pulseras; prohibición o exigencia de gorros o pañuelos en la cabeza, etc.), sino también a su aspecto exterior y aseo personal (prohibición de llevar pelos largos o excesivamente cortos, pelos "trabajados"o pelos teñidos con determinados colores "no naturales", de llevar barba o bigote, de usar excesivamente pinturas y aceites; exigencias en cuanto al uso de maquillaje en el trabajo, de peso corporal o de una elemental limpieza que evite olores corporales, etc.), - y el interés del trabajador en mantener su libertad durante la jornada de trabajo para decidir sobre su propia imagen, entran en conflicto varios derechos constitucionalmente protegidos (por todas, STCO 88/1985, de 19 de Julio):

a) De una parte, el derecho a la "libertad de empresa", reconocida en el Art. 38 de la CE ("Se reconoce la libertad de empresa en el marco de la economía de mercado") y en los Arts. 5.c) ("Los trabajadores tienen como deberes básicos: c) Cumplir las órdenes e instrucciones del empresario en el ejercicio regular de sus facultades directivas") y 20 ("En el cumplimiento de la obligación de trabajar asumida en el contrato, el trabajador debe al empresario la diligencia y la colaboración en el trabajo que marquen las disposiciones legales, los convenios colectivos y las órdenes e instrucciones adoptadas por aquel, en el ejercicio regular de sus facultades de dirección $y$, en su defecto, por los usos y costumbres").

b) De otra parte, con carácter general, el derecho del trabajador al "honor", a la "intimidad personal" y a "la propia imagen", reconocido en el Art. 18.1 de la CE ("Se garantiza el derecho al honor, a la intimidad personal y familiar y a la propia imagen") y en el Art. 4.2 e) del 
ET ("En la relación de trabajo, los trabajadores tienen derecho: e) Al respeto de su intimidad y a la consideración debida a su dignidad"). Si bien, en ocasiones, pudieran concurrir otros derechos, tales como el derecho a la "no discriminación por razón de género" (Arts. 14 de la CE y 4.2 c) y 17.1 del ET), el derecho a la seguridad y salud laboral (Arts. 15 de la CE y $4.2 \mathrm{~d}$ ) del ET), el derecho a "la libertad religiosa" (Arts. 14 y 16.1 de la CE y 4.2 c) y 17.1 del ET) o el derecho a la libertad de expresión (Art. 20 de la CE).

3. La doctrina jurisprudencial y judicial sobre estas cuestiones. A continuación, expondré cuáles han sido los conflictos que han llegado a los Tribunales Superiores (Tribunal Constitucional, Tribunal Supremo, Audiencia Nacional o Tribunales Superiores de Justicia Autonómicos) y cuáles han sido las soluciones dadas a los mismos, con sus correspondientes argumentaciones, siguiendo para ello un criterio cronológico:

\section{1a) STS 11038/1986, de 12 de Febrero y STC 170/1987, de 30 de Octubre}

En la Sentencia del Tribunal Constitucional se resuelve negativamente el recurso de amparo solicitado por un trabajador, primer barman en una empresa hotelera, al que se le ordena afeitarse la barba $y$, ante la reiterada negativa del trabajador, se le sanciona con el despido disciplinario.

El trabajador recurre en amparo, alegando vulneración de los Arts. 24.1 (derecho a la tutela judicial efectiva), 14 (derecho a la igualdad de trato) y 18.1 de la CE (derecho a la intimidad y a la propia imagen) y el Tribunal Constitucional desmonta cada una de estos fundamentos de derecho del recurso del siguiente modo:

a) Alegar por el recurrente que se vulneró el Art. 24. 1 de la CE porque la Sala Sexta del Tribunal Supremo no acordó como prueba para mejor proveer la solicitada por él para acreditar que otra Sentencia del mismo Juzgado de lo Social dictada anteriormente en un supuesto idéntico resolvía el caso en sentido favorable para el trabajador, es olvidar que, según reiterada doctrina del Tribunal Constitucional, "la decisión sobre la pertinencia de las pruebas propuestas por las partes, lo mismo que la valoración de las practicadas, es función que corresponde a los órganos judiciales de conformidad con el Art. 117.3 de la Constitución, sin que este Tribunal pueda revisar tales decisiones, salvo los supuestos en que se justifique que la prueba denegada lesiona el derecho de defensa por ser decisiva o tener influencia notoria para la resolución del pleito o de un punto controvertido de mismo. Y éste no es el caso". Pero, además, "la prueba se ha solicitado para mejor proveer en un recurso de casación en el que... no es dable, en absoluto, aportase ningún elemento de juicio que no lo haya sido en instancia (por) la propia naturaleza del recurso".

b) Tampoco se da infracción del principio de igualdad que consagra el Art. 14 de la Constitución por parte de la Sentencia del Juzgado de lo Social que dicta una sentencia desfavorable para el recurrente contraria a otra anterior del mismo Juzgado, por cuanto que, para que se de la infracción requerida, es necesario "que los casos resueltos respondan sustancialmente a los mismos supuestos de hecho y que no se fundamente o justifique el cambio de criterio del juzgador, el cual puede, naturalmente, en su función de aplicación de la legalidad, evolucionar razonablemente en su proceso interpretativo sin que ello vulnere el principio de igualdad" y ésto es lo que ocurre en el presente caso. 
c) Finalmente, por lo que respecta a la supuesta vulneración del derecho a la intimidad y a la propia imagen de trabajador, argumenta la Sentencia que "no es la decisión personal sobre su apariencia fisica lo que se discute en este proceso, sino si esta decisión puede o no limitarse en virtud de las relaciones laborales en que desarrolla su actividad profesional". Y, en esta perspectiva, se señala que "el punto crucial del litigio consiste en determinar si la orden del empresario excedia o no de sus facultades directivas; $y$, apreciando como hecho probado el uso local en el sector de hostelería de que los empleados que tengan contacto con los clientes deben permanecer afeitados, debe considerarse legitimado al empresario para dar dicha orden (Art. 20.1 del ET) y procedente el despido por el reiterado incumplimiento del trabajador (Art. 54.2 del ET)".

2a) STSJ de la Comunidad Valenciana, de 29 de Mayo de 1996, Ar/1615

El trabajador, en una actividad dedicada a la manipulación de alimentos frescos, comprometido por el contrato expresamente a observar un riguroso aseo personal, por dejarse "una pequeña perilla nada poblada, que ha mantenido muy corta y perfectamente cuidada, habiendo asistido a su puesto de trabajo observando siempre un correcto aseo personal", es requerido por la empresa para que se afeite la barba $y$, ante la negativa del trabajador, es despedido por desobediencia grave.

La Sentencia de instancia declaró la improcedencia del despido, al no acreditarse en este caso "la actitud rebelde de desobediencia" en el trabajador ni tampoco la existencia de un uso o costumbre que prohíba el uso de la barba (en este caso, perilla de las características señaladas), existiendo prueba en contra de que otros trabajadores, también en contacto con el público, llevaban bigote y perilla de largo superior a la del actor.

La Sentencia del Tribunal Superior de Justicia confirmó la Sentencia de instancia, argumentando igualmente que las costumbres no se rigen por el principio "iura novit curia" y que, al no haber sido demostrada en juicio por la empresa, no cabe aplicarla.

\section{3a) STSJ de Cataluña, de 8 de Enero de 1998, Ar/156}

En la presente Sentencia se plantea el caso de un camarero que, reiteradamente, se niega a vestir el uniforme de la empresa y es despedido por ello por desobediencia. Mientras la Sentencia de instancia declara improcedente el despido del trabajador, la Sentencia de suplicación revoca la de instancia y declara el despido procedente.

La argumentación de la Sentencia se basa en la obligación del trabajador de obedecer las órdenes e instrucciones empresariales dentro del ámbito y organización del trabajo, "salvo que la misma pueda comportarle riesgos inminentes o devenga ilegal o atentatoria de su dignidad", cosa que, a su juicio, no se da en el presente caso.

4a) Sentencias de la Audiencia Nacional de 30 de Septiembre de 1999, Ar/4272, del Tribunal Supremo, de 23 de Enero de 2001, Ar/2063 y del Tribunal Constitucional 84/2006, de 27 de Marzo

Establecido para el AVE de RENFE un Manual de Uniformidad para sus trabajadores masculinos (pantalón y calcetines) y femeninos (falda larga, de dos centímetros por encima de la rótula y medias), se plantea conflicto colectivo por el Sindicato Federal Ferroviario de la Confederación General del Trabajo (SFF-CGT), afectando a la totalidad de las trabajadoras, contra el uniforme 
femenino por considerarlo atentatorio de los Arts. 14 a 28 de la Constitución (discriminación por razón de sexo).

La Sentencia de la Audiencia Nacional desestima la demanda y argumenta que "es razonable exigir al personal... una uniformidad especial, que no quede al arbitrio de trabajador, ni un derecho de opción, que al varón no se otorga, cuando el uso de la falda en el ambiente social que nos rodea no se considera discriminatoria por razón de sexo, sino simple manifestación de moda o elegancia, o de disfrute de una comodidad impropia de aquellas otras cualidades...prevaleciendo... las facultades organizativas que al empresario corresponden".

La Sentencia del Tribunal Supremo desestimó el posterior recurso de casación, confirmando la Sentencia de la Audiencia Nacional, argumentando que "ello no acarrea que exista una discriminación en el hecho de imponer la falda litigiosa a ciertas empleadas que tienen relación directa con la clientela, pues la desigualdad de trato no obedece a un motivo sexista, ni se han acreditado factores relevantes que tachen de discriminatoria la exigencia, pues la obligación de uniformidad parece razonable en una empresa pública, que, con la instauración de un novedoso y moderno medio de comunicación, como es el AVE, trata de uniformar a quienes de manera constante y habitual proyectan sobre los clientes la imagen de la Compañia, en condiciones de igualdad con otras empresas dedicadas a idéntica o semejante actividad, por lo que existe una justificación objetiva y razonable que priva a la uniformidad de la empleada de carácter discriminatorio".

Planteado con posterioridad recurso de amparo contra la Sentencia ante el Tribunal Constitucional, comoquiera que la empresa había aceptado extrajudicialmente la reclamación de los trabajadores, señalará éste que "la reparación de los derechos fundamentales que se denuncian vulnerados se ha producido extraprocesalmente con anterioridad a que este Tribunal dicte su decisión, por la desaparición de la causa o acto determinantes de esa hipotética lesión de derechos, que resulta así inexistente en la actualidad, lo que "hace perder sentido a un pronunciamiento del Tribunal Constitucional, al carecer ya de vulneración sobre la que realizarlo. En suma, como la pretensión dirigida al restablecimiento o la preservación de los derechos presuntamente vulnerados se ha visto satisfecha fuera del propio proceso de amparo, cabe concluir "que éste carece desde ese momento de objeto sobre el que deba pronunciarse este Tribunal".

\section{5a) STSJ de Cataluña, de 3 de Diciembre de 1999, Ar/2522}

Un vigilante de seguridad se niega a usar la gorra dentro del centro de trabajo que, como parte del uniforme, ha impuesto la empresa. Y, ante la negativa reiterada del trabajador, es despedido por desobediencia.

La Sentencia, sin cuestionarse en ningún momento la facultad del empresario de imponer un uniforme a su personal, facultad tampoco cuestionada argumentalmente por el trabajador, falla, sin embargo, confirmando la Sentencia de instancia, que el despido es improcedente por entender "totalmente desproporcionada (la medida) en relación con las circunstancias concurrentes".

6a) STSJ de Cantabria, de 17 de Agosto de 2000, Ar/3145

En el presente caso, una trabajadora, camarera en un establecimiento abierto al público, que se coloca un "piercing" en la nariz, es instada por la empresa a quitárselo y, ante la negativa a hacerlo, alegando que "podia producirsele una lesión para la propia salud o aspecto físico si se retiraba el pendiente mientras no cicatrizase la herida", es despedida por desobediencia.

En este supuesto, y así lo confirma expresamente la Sentencia del Tribunal Superior de Justicia, "no se plantea la decisión personal sobre la apariencia física y el problema inmediato de si la actitud 
de colocarse un gran pendiente en la nariz puede o no condicionarse o limitarse en virtud de las exigencias en las que se desarrolla la actividad profesional, es decir, la utilización por el empresario de sus facultades directivas y la trascendencia del uso y costumbre en un determinado sector (de hostelería) frente al ejercicio de la libertad personal y la propia imagen", sino solamente si el despido está o no justificado.

En este último sentido, y confirmando la Sentencia de instancia, el Tribunal Superior declara el despido improcedente, argumentando que "la negativa de la trabajadora a obedecer está fundada en la eventualidad de que se produjera una lesión para la propia salud o aspecto físico si no le podia retirar el pendiente mientras no cicatrizase la herida" y que "se exceptúan del deber de obediencia las órdenes del empresario que afectan a derechos irrenunciables del trabajador, que afectan a su dignidad, sean ilegales $o$, como se aprecia en el caso analizado, concurran circunstancias de peligrosidad u otras análogas que razonablemente justifiquen la negativa a obedecer la orden de la empresa".

\section{7a) STSJ de la Comunidad Autónoma de las Islas Baleares, de 5 de Febrero de 2001, Ar/1348}

Un trabajador, auxiliar administrativo en una Agencia de Viajes, que se niega a utilizar el uniforme suministrado por la empresa (una determinada camiseta), es despedido por desobediencia.

La Sentencia del Tribunal Superior de Justicia, confirmando la Sentencia de instancia, declara el despido procedente por entender que "resulta patente... la indisciplina del trabajador y su firme, decidida y constante voluntad de incumplir la orden de la empresa de emplear una vestimenta determinada durante el trabajo, sin otra razón para desobedecer que su propio capricho, pues ninguna ha aducido para tratar de justificar su actitud".

Aunque no se plantea en el juicio y, por tanto en la Sentencia, la cuestión de fondo de si una empresa puede obligar a sus trabajadores a llevar un uniforme, parece desprenderse tácitamente de la argumentación judicial que tal facultad empresarial se deriva de su poder de organización y dirección del trabajo.

\section{8a) STSJ de la Comunidad Autónoma de Madrid, de 10 de Julio de 2001, Ar/3724}

Ante la negativa a usar el gorro un empleado de cocina en una empresa hostelera, es despedido por desobediencia.

La Sentencia dictada en suplicación revoca la Sentencia de instancia y declara la procedencia del despido, argumentando que el gorro era obligatorio para todo el personal de cocina, con base en el RD 2207/1995-que establece que en las empresas del sector alimentario es obligatorio el gorro de cabeza- y en el Acuerdo Laboral de ámbito estatal para el Sector de Hostelería de 24 de junio de 1996.

\section{9a) STSJ de Andalucia/Granada, de 13 de Noviembre de 2001, Ar/2002/53716}

Un trabajador, que se niega a utilizar la camiseta proporcionada por la empresa con su anagrama, según establece el convenio colectivo aplicable, y utiliza una camiseta distinta con un mensaje reivindicativo, es despedido por ello y la Sentencia dictada en suplicación, confirmando la Sentencia de instancia, declara la procedencia del despido efectuado por la empresa.

En el presente caso, el trabajador alega que la prohibición de utilizar las camisetas reivindicativas atenta contra el derecho fundamental a la libertad de expresión y a la libertad sindical. En este sentido, la Sentencia niega tal acusación y señala que la exigencia de la empresa "no atenta a 
la posible libertad de expresión de los trabajadores y a libertad sindical; otra cosa hubiera sido si en la propia ropa de trabajo suministrada por la empresa, y no en otra distinta, se hubieran incorporado los anagramas y frases publicitarias antes dichas, en cuyo caso, si tal incorporación hubiera sido vetada por la empresa, si pudiéramos entrar a analizar si se viola o no el derecho a la libertad sindical, pero como ése no es el caso, y ciñéndonos a lo que es objeto de debate, no puede decirse que la decisión empresarial impugnada viole tal derecho, por lo que procede confirmar la resolución impugnada".

10a) STSJ de Las Islas Canarias, de 20 de Diciembre de 2001, Ar/2002/159624

La empresa "Eurohandling UTE" publicó unas normas de uniformidad para los trabajadores en las que se señalaba, respecto del personal femenino, lo siguiente:

a) "La chaqueta debe estar completamente abrochada o perfectamente doblada sobre el brazo, pudiéndose en temporada de verano autorizar por el supervisor que se facture sin chaqueta siempre que todos los facturantes vayan iguales, y únicamente debe prescindirse de ella dentro del mostrador".

b) "El maquillaje del rostro debe ser discreto, en tonos naturales, el de los ojos es obligatorio en colores que armonicen con el uniforme y el maquillaje de labios es obligatorio llevarlos siempre pintados, con colores brillo o acordes con el uniforme, señalándose igualmente que los peinados permitidos son pelo corto sin rapados en nuca o patillas, media melena cuya longitud no exceda del cuello, moño no demasiado alto, cola cuya longitud no exceda de los hombros, el flequillo no podrá sobrepasar la altura de las cejas, no permitiéndose peinados ultramodernos".

Los trabajadores plantearon demanda contra la empresa por atentado a los Arts. 14 (principio de no discriminación por razón de sexo) y 18 de la Constitución (derecho a la intimidad y a la propia imagen), obteniendo una Sentencia en instancia denegatoria, que fue más tarde confirmada por el Tribunal Superior de Justicia, con los siguientes escasos "argumentos":

10) En relación con el principio de no discriminación por razón de sexo, señala que "las normas de uniformidad impuestas por Eurohandling en la actividad desarrollada no vulnera el principio de igualdad...; la obligación de uniformidad es razonable en una empresa pública, respondiendo a consideraciones organizativas empresariales adoptadas con la finalidad de dar a la clientela una buena imagen de empresa".

$2^{\circ}$ ) Respecto del derecho a la intimidad y a la propia imagen, señala que los derechos a la intimidad y a la propia imagen quedan "delimitados por las leyes y usos sociales" y que "no se puede afirmar razonablemente, en el contexto y circunstancias laborales en que ha sido tomada la medida empresarial que las reglas de uniformidad, que no alcanzan a la vida privada de los empleados, viole los derechos citados".

3o) Concluye, finalmente, la Sentencia en que es razonable que la empresa adopte la uniformidad en el desarrollo de una actividad y que "la determinación de la uniformidad, en defecto de pacto colectivo o individual de los interesado, es competencia del empleador, salvo naturalmente, que la decisión patronal atente a la seguridad y honor del trabajador o a cualquiera de los derechos fundamentales y libertades públicas reconocidas en la Constitución", cosa que, en este caso, entiende que no sucede. 


\section{1a) STSJ de la Comunidad de Madrid, de 18 de Abril de 2001. Ar/2341}

El trabajador, cocinero de profesión, además del bigote que lucía desde su ingreso en la empresa, aditamento personal aceptado sin mayores problemas por ésta, se dejó una perilla ("recortada y aseada", según reza en los hechos probados), siendo requerido por la empresa a "rasurársela completamente en el plazo de cinco días", fundamentando su decisión en que el trabajador se dedicaba a la manipulación de alimentos, que corresponde a la empresa, según el RD 202/2000, de 11 de febrero, garantizar la salubridad y seguridad de los alimentos y que la menor presencia de cabello visible en los manipuladores implica un menor riesgo de contaminación de los alimentos.

Planteada demanda contra la decisión empresarial, tanto la Sentencia de instancia como la Sentencia de suplicación coinciden en considerar que "no encuentra apoyo en normativa legal o convencional que prohiba a los cocineros llevar bigote y perilla cuando tales adornos capilares...están debidamente recortados y aseados. Si bien es cierto que el Real Decreto 202/200, de 11 de febrero, establece que los manipuladores de alimentos deben cumplir las instrucciones de trabajo establecidas por la empresa para garantizar la seguridad y salubridad de los alimentos, tales instrucciones deben ser razonables y encontrar amparo legal, convencional o consuetudinario, lo que no sucede en este caso, al constatar la sentencia combatida que el trabajador desarrolla su tarea con el debido aseo y cuidado".

\section{2a) STSJ de la Comunidad de Madrid, de 7 de Mayo de 2002, Ar/2042}

Un trabajador, teleoperador de una empresa de telemarketing, decide ir al trabajo con pantalones cortos, por lo que es requerido por la empresa de no hacerlo en adelante. El trabajador se niega a obedecer la instrucción empresarial y envía una carta a la empresa indicándole "quede claro que seguiré con pantalón corto, porque son bonitos y hace calor", copia de cuya carta publica en el tablón de anuncios de la empresa durante los tres días siguientes a su entrega. La empresa despide al trabajador por desobediencia y éste demanda a la empresa, obteniendo Sentencia declaratoria de la improcedencia del despido tanto de la Sentencia de instancia como de la Sentencia de suplicación.

La Sentencia del Tribunal Superior de Justicia argumentará del siguiente modo su postura:

a) En primer lugar, que se trata de una orden empresarial ajena al trabajo, "sobre un extremo que ninguna norma interna consta que existiera al respecto, y que excede de las facultades de dirección de la empresa, pues al margen de una genérica corrección y limpieza que es siempre exigible,...no cabe imponer o rechazar sin más una determinada indumentaria, máxime cuando en el desarrollo de su labor el actor no tenía contacto alguno con el público y, por lo tanto, su modo de vestir no trasciende, ni puede ante terceros afectar a la imagen de la demandada".

b) En segundo lugar, que no es comparable el caso con el resuelto por la Sentencia de la Audiencia Nacional de 30 de septiembre de 1999 (ver supra), "pues no olvidemos que si facultad de la empresa es imponer una determinada uniformidad en el trabajo a sus empleados, no ejerció la recurrente tal facultad aqui, sino que sin existir uniforme ni norma concreta sobre el modo de vestir, ordenó al demandante no usar la prenda concreta pantalón corto".

13a) STSJ de Galicia, de 27 de Junio de 2002, Ar/3521

La Consellería de Sanidad de la Xunta de Galicia establece la obligación para todo el personal de "fichar uniformado a la entrada y salida del turno de trabajo", siendo tal orden empresarial impugna- 
da judicialmente por considerarla atentatoria del derecho a la intimidad y a la propia imagen de los trabajadores (Art. 18.1 de la Constitución).

Tanto la Sentencia de instancia como la Sentencia de suplicación deniegan la pretensión de la demanda, considerando que no resulta atentatoria del derecho fundamental alegado. Las argumentaciones son las siguientes:

a) En primer lugar, porque la exigencia de uniforme de trabajo está reglamentada, tanto por el Convenio Colectivo para el personal laboral de la Xunta de Galicia, como por una Orden Ministerial de 4 de junio de 1992 (reguladora de la exigencia de uniforme en los centros socio-sanitarios) y por una Resolución de la Dirección General de Relaciones Laborales de la Xunta de 15 de marzo de 2000, sobre la uniformidad en los centros de la Xunta de Galicia.

b) En segundo lugar, porque la orden empresarial "lo que exige es fichar uniformado al entrar o salir del turno de trabajo, no antes ni después, debiendo ello situarse en el contexto que supone la diferenciación cierta entre centro de trabajo y puesto de trabajo, entre jornada (tiempo de presencia física en el centro de trabajo) y jornada de trabajo ... y la significación al hilo de ello del fichaje de control horario que se hace dentro del centro de trabajo".

14a) STSJ de la Comunidad Autónoma de las Islas Baleares, de 9 de Septiembre de 2002, Ar/2003/3

Un trabajador de la Empresa Municipal de Transportes, miembro de la Comunidad Israelita de Mallorca, durante la conducción del autobús lo hace con kipá, siendo así que el Convenio Colectivo que regula el uniforme de los trabajadores no incluye la gorra dentro del mismo. La empresa incoa por ello expediente disciplinario al trabajador y le sanciona. El trabajador impugna judicialmente la sanción con base en el derecho a la libertad religiosa del Art. 16.1 de la Constitución y las sentencias, de instancia y de suplicación, estiman la demanda y declaran el derecho del trabajador a conducir con gorra.

Las argumentaciones utilizadas por la Sentencia para llegar a esta conclusión son las siguientes:

a) En primer lugar, que "no existen derechos ilimitados, y el derecho de la empresa a imponer a sus empleados el uso de un determinado uniforme cabe por ello que ceda si colisiona con un derecho al que atribuirse rango preponderante. La orden empresarial de vestir una determinada ropa no puede lesionar la dignidad o el honor del trabajador o cualquiera de los derechos fundamentales y libertades públicas constitucionalmente consagrados. El empeño del aqui actor en llevar gorra mientras conduce el autobuis no obedece a un mero capricho o al seguimiento de modas. Aunque la sentencia no lo consigne, de manera sorprendente, entre los que declara probados, es hecho clave alegado en la demanda y corroborado de pleno en juicio que aquél es miembro de la Comunidad Israelita de Mallorca y practicante de la religión judía, desde hace unos 23 años, así como que esta creencia considera necesario tener siempre cubierta la cabeza en señal de respeto a la divinidad. Usar gorra, asi pues, constituye para el demandante un acto prescrito por su religión, de manera que el conflicto se plantea entre el derecho de la empresa a dirigir la actividad laboral (Art. 20.1 del ET) y el derecho fundamental a la libertad religiosa de uno de sus empleados (Art. 16.1 de la Constitución, desarrollado por la Ley Orgánica 7/1980, de 5 de julio), derecho fundamental que, como recuerda la STCO 154/2002, de 18 de julio, incluye, junto a la garantía de la existencia de un claustro intimo de creencias y, por tanto, de un espacio de autodeterminación intelectual ante el fenómeno religioso, una dimensión externa de "agere licere" que faculta a los ciudadanos para actuar con arreglo a sus propias convicciones y mantenerlas frente a terceros" (SS.TCO 19/1985; 120/1990; 137/1990)". 
b) En segundo lugar, no obstante, la Sentencia matiza y señala prudentemente que "un conficto de las caracteristicas del que aqui se examina no admite una solución única. Dependerá de las circunstancias que concurran en cada situación concreta, ponderando hasta quépunto el comportamiento del trabajador a que le obligan sus convicciones religiosas resulta inocuo para los intereses de la empresa o, por el contrario, incompatible con ellos. En el caso de autos, no consta que la conducta del actor haya causado algún tipo de daño o menoscabo a la imagen de la empresa, incidente o trastorno cualquiera durante la ejecución del servicio o, más en general, ninguna clase de perjuicio".

\section{5a) STSJ de la Comunidad Autónoma de Cantabria, de 12 de Marzo de 2003, Ar/2708}

Se le imputa al trabajador que el día de su reincorporación al trabajo después de una baja de cuatro meses vestía indumentaria inadecuada (pantalones cortos de deporte o bañador, chaleco sin mangas, brazos al descubierto y sin afeitar), además de otros hechos (ausencias injustificadas, falta de respeto a la dirección, faltas de puntualidad, realización de grabaciones no consentidas de las conversaciones en el centro de trabajo, falta de entrega a la empresa del parte de alta médica y desobediencia), por lo que se le despide.

El trabajador impugna el despido y la Sentencia de instancia lo declara procedente, si bien la Sentencia de suplicación revoca la Sentencia de instancia y declara la improcedencia del despido, alegando, entre otras cosas, que "l Código de Conducta tipifica como falta grave (no sancionada con despido) la falta de aseo y limpieza personal que produzca quejas justificadas de los compañeros de trabajo y siempre que previamente haya mediado la oportuna advertencia por parte de la empresa, por lo que ni siquiera se cumplen en este caso los requisitos del tipo de la falta grave y aún si se cumpliesen la sanción no podría ser la de despido".

\section{6a) STSJ de la Comunidad Autónoma de las Islas Baleares, de 7 de Octubre de 2003, Ar/630}

Una trabajadora de una empresa del Sector del Transporte Aéreo se niega a obedecer las órdenes del encargado de ponerse el chaleco reflectante para realizar su trabajo en las pistas del aeropuerto y es despedida por ello. La trabajadora demanda a la empresa por el despido y, tras la calificación del despido como improcedente por la Sentencia de instancia, el Tribunal Superior de Justicia revoca la Sentencia de instancia y declara la procedencia del despido.

La Sentencia fundamenta su posición en el carácter obligatorio, por razones de seguridad, del uso de los chalecos reflectantes para acceder a las pistas, por así ordenarlo las medidas de seguridad impuestas por AENA, entendiendo que la negativa de la trabajadora a su uso, lo que determinó que se le impidiera prestar sus servicios, constituye una conducta grave y culpable de la trabajadora por desobediencia, justificativa del despido.

\section{7a) STSJ de Galicia, de 26 de Enero de 2007, Ar/205724}

Un trabajador, oficial de $1^{\text {a }}$ carnicería, entró en repetidas ocasiones en el laboratorio de carnicería sin la ropa de trabajo adecuada, sin gorro y sin mascarilla, en claro incumplimiento de la normativa obligatoria al uso, siendo requerido por ello por el jefe de sector. La empresa le despide por esta conducta y el trabajador impugna judicialmente el despido, manifestándose las Sentencias de instancia y de suplicación en el sentido de calificar el despido como procedente. 
La Sentencia argumenta la procedencia del despido en base a la gravedad de la conducta, dado que el acceso y la permanencia del trabajador en el laboratorio de carnicería sin los medios de seguridad obligatorios fue recurrente, máxime tratándose de un trabajador cualificado y habiendo sido además requerido específicamente por el Jefe del sector.

18a) STSJ de Cataluña, de 16 de Junio de 2005, Ar/1771

Un trabajador, vigilante de seguridad, es despedido por llevar solamente parte del uniforme de la empresa (los pantalones eran de paisano y la camisa de rayas, camisa que había quedado inhabilitada por el nuevo uniforme), además de por ausentarse del puesto en una determinada ocasión. Impugnado judicialmente el despido, tanto la Sentencia de instancia como la de suplicación estiman la improcedencia del despido, argumentando, con base en la conocida "teoría gradualista" de la jurisprudencia a la hora de enjuiciar las circunstancias justificativas de un despido (antigüedad del trabajador en la empresa, escaso o nulo perjuicio económico sufrido por la empresa y la inexistencia de otras sanciones anteriores por el mismo hecho), sin que en ningún caso se ponga en cuestión el derecho de la empresa a exigir el cumplimiento del uniforme de empresa por ella establecido.

\section{9a) STSJ de Galicia, de 26 de Enero de 2007}

Considera la Sala que "el acceso y la permanencia del trabajador en el laboratorio de carnicería sin los medios de seguridad obligatorios fue recurrente, máxime tratándose de un trabajador cualificado y habiendo sido además requerido especificamente por el Jefe del sector", incumplimiento que determinó su despido procedente.

\section{0a) STSJ de la Comunidad Autónoma de Madrid, de 5 de Noviembre de 2007, Ar/3506}

Un trabajador, en una empresa concesionaria de automóviles, con la categoría profesional de viajante, se presentó un día en el centro de trabajo con una camiseta deportiva, con número dorsal, pantalones vaqueros y zapatillas de deporte. Mediante carta de la misma fecha, la empresa le impuso una sanción de suspensión de empleo y sueldo de un día por falta grave, considerando que su puesto de comercial con atención al público hacía inadecuada la vestimenta y era perjudicial para la imagen de la marca. Al día siguiente, el actor se vuelve a presentar en el centro de trabajo de la misma guisa. Mediante carta de ese día, la empresa le impuso una nueva sanción de empleo y sueldo, esta vez de doce días, por falta grave. Al día siguiente, nuevamente el actor volvió a comparecer con la misma vestimenta en la empresa. Esta, mediante carta de la misma fecha, comunicó al actor su despido inmediato, aludiendo a su conducta inadecuada y provocativa, a los requerimientos que le habían sido hechos para que no acudiese al trabajo con una vestimenta tan informal y a las dos sanciones precedentes. En la empresa, en el departamento comercial, habitualmente se acudía a trabajar vestido con traje y corbata de cara al público, y que solo se utiliza una vestimenta algo menos formal, pero elegante en todo caso, cuando se realiza un inventario o se retiran coches de eventos celebrados en el extranjero.

Demandada la empresa por despido, tanto la Sentencia de instancia como la Sentencia de suplicación coinciden en calificar el despido de procedente, argumentando de la siguiente forma: "Es de conocimiento común que determinadas actividades laborales requieren una minima corrección o pulcritud indumentaria conforme unas reglas de trato social comúnmente admitidas, que por ello se dan por supues- 
tas sin necesidad de un acuerdo expreso. Siendo ello así, quien aceptó prestar tareas de aquella indole carece de justificación para eximirse de las obligaciones que al respecto y conforme a esos usos sociales requiera el desempeño de sus cometidos profesionales. En el supuesto examinado, la indole de las tareas profesionales encomendadas al demandante comportaba, mientras las desempeñaba, obvias limitaciones en su libertad de vestir a su antojo. Por añadidura, el modo de actuar del demandante, al hacer caso omiso de manera reiterada de las lógicas advertencias y amonestaciones de la empresa, exterioriza un indudable propósito de indisciplina e incluso de provocación, tan perceptible, que esta Sala apenas ha de esforzarse por argumentar lo obvio, dado que resulta patente la insumisión del trabajador y su firme y decidida voluntad de incumplir la orden de la empresa de que no volviera a acudir a su trabajo con una vestimenta inadecuada según esos usos sociales. El comportamiento del trabajador demandante contravino claramente el legitimo poder de dirección del empresario (Arts. 5 c) y 20.1 del ET) y merece indudablemente el despido en recta aplicación del Art. 54.2 b) del ET; la conducta descrita, reiterada por el trabajador en tres diferentes dias del mes de julio de 2006, evidencia un clara indisciplina y vulneración de la buena fe contractual, con las notas de gravedad y culpabilidad que determinan la procedencia del despido".

21a) STSJ de Cataluña, de 23 de Julio de 2008, Rec. 3296/2008

La Sentencia considera que la exigencia por parte de la empresa del uso obligatorio de una gorra, que ésta facilita, a los vigilantes de seguridad que realizan sus servicios en una estación ferroviaria no obedece a una decisión arbitraria empresarial sino que se justifica por el lugar donde se presta el servicio, ya que facilita el más pronto reconocimiento de los mismos por parte de los usuarios de los servicios ferroviarios.

22a) STSJ de AndalucialMálaga, de 27 de Noviembre de 2008, Rec. 2/2008 y STS de 19 de Abril de 2011, Rec. 16/2009

El TSJ de Málaga entiende que no existe discriminación en la conducta de la empresa exigiendo al colectivo de enfermeras y auxiliares de enfermería que prestan servicios en planta y consultas externas de llevar falda, delantal, cofia y medias como prenda obligatoria, sin posibilidad de opción por el pijama que usa el personal masculino: "Dicho uniforme no constituye una extralimitación de su facultad directiva, sino una manifestación del poder de dirección del empresario a que hace referencia tanto el Art. 5 c) como el Art. 20.1 del ET, cual es el ejercicio de sus facultades directivas y organizativas, exigiendo a sus trabajadores una determinada uniformidad en el vestir para, conforme dispone el Art. 19.2 del Convenio Colectivo, velar por la buena imagen de sus profesionales y lograr una más fácil identificación de la categoría y función de los mismos".

La STS casa la Sentencia anterior considerando que la práctica empresarial adoptada sobre la uniformidad que han de seguir las mujeres enfermeras o auxiliares de enfermería que prestan servicios en la empresa en planta y consultas externas, consistente en exigir que lleven en su trabajo falda, delantal, cofia y medias, sin posibilidad de optar por el conocido pijama sanitario de dos piezas, que llevan los trabajadores masculinos. "resulta discriminatoria por contener ilícita distinción entre hombres y mujeres y no permitir a éstas la utilización de la prenda de uniforme que utilizan los hombres en las mismas dependencias y con las mismas categorías, el pijama sanitario". 
La Sentencia argumenta que "la imposición del uso de zapatos de tacón a las mujeres y a los trabajadores zapato plano, en palabras del Tribunal Supremo es un componente de distinción vinculado al sexo de las trabajadoras que al resultar obligatorio para ellas y no permitírseles que calcen zapatos sin tacón que sí utilizan los hombres de su misma categoria, supone una actitud empresarial que no resulta objetivamente justificada y por ello discriminatoria, pues, al igual que en la sentencia transcrita, de esa forma, lo que se evidencia y pretende con esa politica empresarial de uniformidad obligatoria y caracteristica para las mujeres, es proyectar al exterior una determinada imagen de diferencias entre hombres y mujeres que no se corresponde con una visión actual de los organismos públicos, lo que también pone de manifiesto que no resulta proporcional la medida en relación con el derecho de igualdad y no discriminación, ni es necesaria, pues si se concediera por la empresa la opción de llevar zapatos de tacón o planos a las trabajadoras que asi lo desearan, ello permitiría también que se materializase la comprensible finalidad pretendida por la empresa de uniformidad de sus empleados para que los usuarios conozcan en todo momento la calidad o condición de guia, como ocurre con los hombres que hacen la misma función, actuación empresarial que es aún más gravosa teniendo en cuenta que hombres y mujeres realizan idéntica tarea en posición de bipedestación y que el uso de tacones altos es innecesario y no solo no aporta ningún beneficio ni ventaja, sino por el contrario puede perjudicar la salud de las trabajadoras dado que si les resultan incomodos, la incomodidad puede traducirse en cansancio cuando llevan varias horas de pie y en lesiones y además puede llegar a repercutir en su rendimiento y en la atención al público, por lo que hemos de concluir que la orden dada a la trabajadora por la empresa vulnera el artículo 14 de la Constitución y es consecuentemente nula, lo que justifica la falta de acatamiento por su parte”.

\section{4a) STS de 3 de Junio de 2015, Ar/1178/2015}

Planteada la cuestión de si la exigencia empresarial de acudir maquillada al trabajo es discriminatoria del derecho fundamental a la propia imagen cuando en la normativa interna de la empresa se establece la exigencia, no de ir maquillada, sino, en el caso de ir maquillada, de llevar un "maquillaje discreto".

Habiéndose acreditado que la actora no iba maquillada y que no accedió a maquillarse, se entiende que la actuación de la empresa, imponiéndole tal exigencia, constituye una clara lesión del derecho fundamental de la trabajadora a su propia imagen (Art. 18.1 de la CE), pues suponía una seria intromisión, totalmente injustificada, en un aspecto relacionado claramente con la imagen más básica de la persona, esto es, en su libertad para mostrar su imagen física personal, lo que determina la nulidad del despido.

25a) STSJ de AndalucialMálaga, de 19 de Noviembre de 2015. Rec. 1340/2015

El trabajador presta servicios para una entidad aseguradora como tramitador de siniestros. Sus funciones implican relaciones externas con médicos, abogados, lesionados, investigadores y entidades aseguradores. La empresa cuenta con un manual de vestimenta profesional de obligado cumplimiento para los empleados que establece, que la vestimenta para los hombres se caracteriza por traje de chaqueta con corbata, americana y pantalón con corbata, camisa de manga larga y zapatos formales. Planteada demanda para que la empresa le facilite la vestimenta y el calzado o, en su lugar, una cantidad por su valor, el TSJ considera, que en el convenio colectivo aplicable se distingue entre las prendas de trabajo y equipos de protección que la empresa debe facilitar a sus trabajadores por 
razones de seguridad y salud laborales y la indumentaria del personal que tenga trato con clientes o terceras personas ajenas a la empresa y que, mientras los primeros deben ser facilitados por la empresa, el costo de la vestimenta profesional corresponde al trabajador.

Por lo demás, el TSJ considera que esta exigencia de la empresa es legítima ya que la finalidad es perseguir una imagen de decoro de sus empleados que redunda en el bien empresarial siempre que no se sobrepase, claro está, las reglas de trato social comúnmente admitidas y que si el trabajador ha aceptado la prestación de servicios en dicho régimen de indumentaria, que ni limita ni lesiona el derecho al honor, dignidad o propia imagen del trabajador, no puede ahora intentar eximirse de su cumplimiento o solicitar el pago de la indumentaria.

\section{6a) SAN de 25 de junio de 2018, Rec. 103/2018}

El cambio de la ropa de trabajo y la forma de gestionarlo adoptada por la empresa no incumple lo dispuesto en el Convenio Colectivo aplicable, al haberse respetado por la empresa las facultades reconocidas al Comité Intercentros y Comité Intercentros de Seguridad y Salud sobre la materia: "La facultad de participar no puede confundirse con la obligación de negociar y alcanzar acuerdo que no se establece en el convenio, y ante la falta de acuerdo, puede decidir la empresa, al ser deudor de seguridad".

4. Conclusiones operativas. A la vista de la doctrina judicial y jurisprudencial repasadas, es posible obtener algunas conclusiones provisionales acerca de las líneas maestras de la misma:

1a) Es doctrina ciertamente consolidada que la exigencia empresarial de un "uniforme" al personal por razones de "imagen de empresa" entra dentro del poder de organización y dirección de la empresa, salvo que existan pactos colectivos o individuales en contrario. Y, aun en el caso de existencia de convenio colectivo sobre el tema, no se cuestiona judicialmente en ningún momento lo que éste dice. En estos casos, parecería que los derechos fundamentales ceden absolutamente a los poderes empresariales, sin tener en cuenta los juicios de idoneidad, necesidad y proporcionalidad de la medida, esto es, sin tener en cuenta las circunstancias (necesaria identificación del personal cara a terceros, eventuales discriminaciones o, en general, exigencias objetivas del tipo de trabajo) (ver supra, Sentencias $3^{\mathrm{a}}, 4^{\mathrm{a}}, 7^{\mathrm{a}}, 8^{\mathrm{a}}, 9^{\mathrm{a}}, 10^{\mathrm{a}}$ y $13^{\mathrm{a}}$.

$2^{a}$ ) En sentido contrario al anterior, cuando no existe una decisión empresarial de uniformar, es cuando juegan jurisprudencialmente con mayor fuerza las circunstancias concurrentes, esto es, se tienen en cuenta los usos y costumbres profesionales, el que el trabajo sea o no cara al público, las nuevas modas y, en general, la razonabilidad de las exigencias empresariales. Así, se llega a admitir como correcta la presencia en la empresa del trabajador que no trabaja cara al público en pantalón corto (ver supra, Sentencia 12a) o incluso en bañador, aunque en este caso conectándolo, extrañamente, con la "falta de aseo" (ver supra, Sentencia 15a). Sin embargo, cuando las exigencias de imagen resultan claras, en la situación de un comercial, la imposición empresarial de un atuendo adecuado es justificada por la Doctrina Judicial (ver supra, Sentencia 20a).

$3^{\text {a) }}$ Desde luego, resultan claras las exigencias empresariales de determinados atuendos en los casos en que están en juego razones de orden público. Así, la seguridad o salud laboral (ver supra, Sentencia 16a) o la seguridad y salubridad de los alimentos (ver supra, Sentencia $17 \mathrm{a})$. 
4a) A partir de la STJUE de 14 de Marzo de 2017, la prohibición de llevar símbolos religiosos en el trabajo no se consideraría un atentado a la libertad religiosa si se refiriese a "cualquier simbolo" (ver, en este sentido, la STJUE de 14 de Marzo de 2017, Asunto CV157/15; en contra Sentencia 14a).

5a) En definitiva, la imagen del trabajador pertenece en principio al empresario durante la jornada laboral, siempre que no se exceda proporcionalmente en sus exigencias a la vista de las circunstancias concurrentes. En este sentido, parecería que, al menos obiter dicta, los límites habría que encontrarlos en la dignidad (ver supra, Sentencia $3^{\mathrm{a}}$ ) u honor (ver supra, Sentencia 10a) del trabajador, por más que los Tribunales Laborales hayan sido reacios a conectar estos derechos con la indumentaria femenina (uso obligatorio de falda: ver supra, Sentencia $3^{\text {a }}$; u otros aspectos de la apariencia externa, tales como el maquillaje, el tipo de corte de pelo o el peinado de los mujeres trabajadoras: ver supra, Sentencia 10a).

6a) Ocasionalmente se aprecia como la "teoría gradualista" se utiliza como base para atenuar la gravedad del incumplimiento del trabajador en materia de uso de uniformes (ver supra, Sentencia $5^{\circ}$ ), aunque sin cuestionar el derecho empresarial a exigir un uniforme (ver supra, Sentencia $18^{\mathrm{a}}$ ).

7a) En aspectos distintos al uniforme o indumentaria propiamente dichos, habría que llamar la atención sobre algunas Sentencias relacionadas con el uso de la barba, que no se validará cuando contradiga un uso local en el sector de la hostelería (ver supra, Sentencia $1^{a}$ ), pero que se considerará lícita cuando se trata de perillas "recortadas y cuidadas", no existiendo uso profesional en contra (ver supra, Sentencias $2^{\text {a }}$ y $11^{\text {a }}$ ).

También, como cuestión original y diferente, cabe resaltar la validación judicial del uso de un piercing, si bien el fundamento de la Sentencia se apoya más en razones sanitarias que en razones de imagen (ver supra, Sentencia $6^{a}$ ).

$8^{a}$ ) En todo caso, ante la ausencia de una normativa legal, reglamentaria y aun convencional sobre este tipo de conflictos de derechos constitucionales, se echa en falta en la solución judicial de los conflictos en esta materia una más cuidadosa aplicación metodológica de la doctrina del Tribunal Constitucional sobre el "equilibrio de los derechos constitucionales", realizando en todos los casos, metodológicamente, el triple juicio de idoneidad, necesidad y proporcionalidad de la exigencia empresarial limitativa de los derechos de los trabajadores a su intimidad y propia imagen, llegándose a cuestionar, en el caso de que tal normativa existiera, la legalidad de la misma, especialmente en cuanto a de los protocolos establecidos en los convenios colectivos, a través del mismo método de valoración anterior.

Por lo demás, pese a las razones siempre existentes de seguridad jurídica, tengo enormes dudas acerca de la conveniencia de que, en una materia tal circunstanciada y variable con los tiempos como es ésta, resulte oportuna una legislación de desarrollo constitucional que pretenda sentar las bases para la solución de estos conflictos entre derechos constitucionales. 